\title{
The Impact of Service Quality and Student Satisfaction at the Faculty of Engineering Andalas University
}

\author{
Dedison Gasni ${ }^{1}$, Rudy Fernandez ${ }^{2}$ \\ \{ d.gasni@ft.unand.ac.id ${ }^{1}$, rfernandez@eng.unand.ac.id ${ }^{2}$ \} \\ ${ }^{1}$ Mechanical Engineering Dept., Faculty of Engineering Andalas University, Padang, Indonesia \\ ${ }^{2}$ Electrical Engineering Dept., Faculty of Engineering Andalas University, Padang, Indonesia
}

\begin{abstract}
The purpose of this study is to address how quality of service influences higher education quality of graduates and the role that student satisfaction and service quality play in this relationship. A quantitative methodology approach was developed. A questionnaire was developed and deployed as a survey for group of students on Engineering Faculty, Universitas Andalas. A total of 461 responses were received using convenience sampling technique and were analyzed. Findings revealed that service quality model could help the faculty of engineering for making improvement in all of aspects of higher education service. From the gap analysis, the faculty of engineering can get information in which areas should be improved in order to increase service quality. There is a positive correlation between dimension of service quality and student satisfaction
\end{abstract}

Keywords: Service Quality, Student Satisfaction, Higher Education.

\section{Introduction}

Higher education has important role in achieving economic development and has allocated fiscal, physical, and human resources and created entrepreneurship systems within the institutions to advance economic development. This role will not only increase the changes in technology, globalization, and demographics a country but also has the capacity, knowledge, and research necessary to improve productivity and adopt an innovative spirit. The higher education will be a dominant factor in preparing workers with the robust skills needed to adapt to changing job requirements. The quality of workers is prepared by higher education through instructional programs, matching instruction to the needs of business and industry, and helping individuals learn throughout their lives. Higher education is also expected to develop a learning community where student can develop holistic competencies for a global society [1].

Throughout instructional programs, higher education offers quality programs and services and continually improves these programs to ensure teaching and learning excellence. The teaching excellence is the key a strong and growing regional economy [2]. Students are primary stakeholders for higher education institution by assessing service quality from their viewpoint, it is crucial for making improvement on teaching and learning programs [3]. 
Based on the consumer behaviour of theory in education, students can be regarded as primary costumers who receive the educational services [4]. Students purchase the services provided by education: therefore, the students have the right to obtain the best quality of education. To improve the quality services, the higher education must understand their needs. To understand their needs, the quality attributes embraced by customers must be understand.

To define service quality in higher education, it is important to clarify both the 'service' and the 'quality' construct. A service in higher education is focus to provide quality learning experiences to students as its costumers through effective learning process [5]. A service has no physical form and it is produced and consumed at the same time. Parasumaran et al. [6] divide into three characteristics of services: intangibility, heterogeneity, and inseparability. In the higher of education, quality is difficult to define of quality because it is depend on every stakeholder [7]. For example, quality in the student perspective is determined by the expectations of individual student [8]. The definition of quality of service in higher education is the difference between what a student expects to receive and his/her perceptions of the actual delivery [9]. Parasumaran et al. [6] define quality of service as the gap between expectations and perceptions of service receiver.

The dimensions of quality of service were proposed by Parasumanan et al.[6] and they were well known as the five dimension of SERVQUAL scale of contemporary quality of service. The five dimensions of SERVQUAL are reliability, assurance, tangibles, empathy and responsiveness, for measurement of quality of service (as shown in Table 1). The measurement of quality of service in the higher of education relates to the dimension of service quality - the SERVQUAL model. The SERVQUAL model is known as the gap model which is identified the gap between customer expectations and customer perceptions.

SERVICE QUALITY = PERCEPTIONS - EXSPECTASIONS[10]

Table 1. The five dimension of Service quality

\begin{tabular}{|c|c|c|}
\hline No. & Dimensions & Remarks \\
\hline 1 & Reliability & Capability to provide the promised service accurately and dependably. \\
\hline 2 & Assurance & $\begin{array}{l}\text { Courtesy and knowledge of personnel and ability to convey confidence } \\
\text { and trust }\end{array}$ \\
\hline 3 & Tangibles & Physical facilities, equipment, appearance, of personal etc. \\
\hline 4 & Empathy & Attention provided to individual customer. \\
\hline 5 & Responsiveness & Willingness to provide prompt service and help customer. \\
\hline
\end{tabular}

The SERVQUAL model has been used by many researchers [1,10,11] for assessing quality of service in higher education focusing on the role of students as primary customers by measuring the gap between their expectations and perceptions. The negative gap in the five dimension of SERVQUAL model can be used not only to improve educational service quality [10] but also to provide relevant information in which areas improvement is necessary in order to enhance service quality[11].

The extent to which an institutions service performance meets the reckoning of the students is known as student satisfaction [12]. Satisfaction of students is affected by students' expectations and their perception about services and quality of services provided [13]. Gathering student opinions about all aspect of academic life is a way to determine student satisfaction. The measurement of satisfaction deal with measuring what students feel about a service that is received and consumed. Feelings can be expressed about the ability of university to meet student's expectations of university and the university experience as a whole. 


\section{Methods}

This research is a cross-sectional study where primary data were obtained using quantitative approach from undergraduate students of Engineering Faculty, Andalas University. To save expenses and times, a convenience sampling technique was used. Service quality showed an enhancing impact on student satisfaction [6]. This study was measuring the effect of service quality on student satisfaction by using internal quality assurance assessment results. The research hypotheses for this research are as follows:

H1 : There is a negative gap between student expectations and perceptions

H2 : SERVQUAL Model can be used to determine in which area improvements should be made by institution.

H3 : SERVQUAL dimensions have a positive influence on student satisfaction.

Likert-type scales were used for items measuring service quality and student satisfaction with response categories from $1=$ strongly disagree to $7=$ strongly agree. Whereas, likert-type scales were used for items measuring Internal Quality Assurance Assessment with response categories from $1=$ strongly disagree to $7=$ strongly agree. The research was conducted at Faculty of Engineering Andalas University. The total number of students enrolled in academic year 2018/2019 was 3069. A sampling rate of $10 \%$ was set and the total number of students in the sample was $\mathrm{N}=461$.

The essential pillar of the the research process is to guaranty that the instruments are reliability. Reliability of experiment is achieved when an experiment gives the same results repeatedly [14]. According to Murphy and Balzer [15], the value of Cornbach's coefficient of above 0.7 is considered suitable and reliable.

Table 2. Reliability analysis

\begin{tabular}{llll}
\hline No. & Dimension & No. of items & Cronbach Alpha $(\boldsymbol{\alpha})$ \\
\hline 1. & Service Quality Perceptions & 25 & 0.937 \\
\hline 2. & Service Quality Expectations & 25 & 0.962 \\
\hline 3. & Student Satisfaction & 24 & 0.942 \\
\hline
\end{tabular}

\section{Results and Discussion}

\section{Demographic profiles and Frequency}

The number of students in the population, frequency, and per sent of each of demographic features are shown in Table 3.

Table 3. Demographics of Survey Respondent

\begin{tabular}{lccc}
\hline Demographic features & $\begin{array}{l}\text { Number of students in } \\
\text { the population }\end{array}$ & Frequency & Persent \\
\hline Study Programs: & 695 & 104 & \\
1. Mechanical Engineering & 857 & 129 & $22.56 \%$ \\
2. Civil Engineering & 527 & 79 & $17.14 \%$ \\
3. Industrial Engineering & 579 & 87 & $18.87 \%$ \\
4. Electrical Engineering & 411 & 62 & $13.45 \%$ \\
5. Environmental Engineering & 3069 & 461 & $100.00 \%$ \\
Total & & & \\
\hline
\end{tabular}




\begin{tabular}{lccc}
\hline Gender: & & & \\
1. Male & 1996 & 299 & $64.86 \%$ \\
2. Female & 1073 & 162 & $35.14 \%$ \\
Total & 3069 & 461 & $100.00 \%$ \\
\hline Level of Study: & & & \\
1. 1st year of study & 799 & 119 & $25.81 \%$ \\
2. 2nd year of study & 779 & 116 & $25.16 \%$ \\
3. 3rd year of study & 766 & 114 & $24.73 \%$ \\
4. 4th year of study & 752 & 461 & $24.30 \%$ \\
Total & 3069 & & $100.00 \%$ \\
\hline
\end{tabular}

This research was conducted using a structured questionnaire with 25 questions for each scale: one to measure student's expectations and one to measure student's perceptions. The SERVQUAL model has five dimension, namely: reliability, assurance, tangibles, empathy, and responsiveness. All of the five dimensions were covered with 25 questions, and the structure of the questionnaire is shown in Table 4.

Table 4. Dimensions and questions in the questionnaire

\begin{tabular}{rcc}
\hline No. & Dimensions & Questions \\
\hline 1. & Reliability & $1-4$ \\
2. & Assurance & $5-10$ \\
3. & Tangibles & $11-13$ \\
4. & Empathy & $14-19$ \\
5. & Responsiveness & $20-25$ \\
\hline
\end{tabular}

Table 5. Comparison of students' expectations and perceptions

\begin{tabular}{lllll}
\hline Dimension & Mean & SD & Min - Max & 95\% CI \\
\hline Electrical Engineering & & & & \\
Perception & 5.161 & 0.803 & $3.16-6.56$ & $4.989-5.332$ \\
Expectation & 5.135 & 0.857 & $3.08-7.00$ & $4.953-5.318$ \\
Student Satisfaction & 5.107 & 0.631 & $3.75-6.96$ & $4.972-5.241$ \\
Gap & 0.0257 & 1.214 & $-2.96-3.16$ & $-0.233-0.284$ \\
\hline Industrial Engineering & & & & \\
Perception & 5.148 & 0.682 & $4.08-6.92$ & $4.996-5.301$ \\
Expectation & 5.952 & 0.842 & $4.28-7.00$ & $5.763-6.141$ \\
Student Satisfaction & 5.108 & 0.558 & $3.21-6.67$ & $4.983-5.233$ \\
Gap & -0.803 & 0.876 & $-2.60-1.24$ & $-0.999--0.607$ \\
\hline Environmental Engineering & & & & \\
Perception & 5.072 & 0.851 & $3.88-7.00$ & $4.856-5.288$ \\
Expectation & 5.289 & 0.717 & $4.00-7.00$ & $5.107-5.471$ \\
Student Satisfaction & 4.936 & 0.650 & $4.00-7.00$ & $4.771-5.101$ \\
Gap & -0.217 & 0.898 & $-2.04-1.72$ & $-0.445-0.011$ \\
\hline Mechanical Engineering & & & & \\
Perception & 5.111 & 0.851 & $3.04-7.00$ & $4.946-5.277$ \\
Expectation & 5.388 & 0.839 & $3.16-7.00$ & $5.224-5.551$ \\
Student Satisfaction & 5.150 & 0.696 & $3.54-7.00$ & $5.015-5.285$ \\
Gap & -0.276 & 1.024 & $-3.48-3.48$ & $-0.476--0.077$ \\
\hline
\end{tabular}




\begin{tabular}{lllll}
\hline Civil Engineering & & & & \\
Perception & 5.195 & 0.832 & $3.28-7.00$ & $5.049-5.341$ \\
Expectation & 5.394 & 0.828 & $3.44-7.00$ & $5.249-5.539$ \\
Student Satisfaction & 5.133 & 0.668 & $3.75-7.00$ & $5.016-5.250$ \\
Gap & -0.199 & 0.894 & $-3.16-2.12$ & $-0.355--0.043$ \\
\hline Engineering Faculty & & & & \\
Perception & 5.145 & 0.808 & $3.04-7.00$ & $5.071-5.219$ \\
Expectation & 5.425 & 0.861 & $3.08-7.00$ & $5.346-5.504$ \\
Student Satisfaction & 5.101 & 0.648 & $3.21-7.00$ & $5.042-5.161$ \\
Gap & -0.280 & 1.018 & $-3.48-3.84$ & $-0.374--0.187$ \\
\hline
\end{tabular}

The gap between expectations and perceptions of the provided service from the students' point of view is shown on Table 5. In the table, the comparison of student's expectations and perceptions is presented. In Table 5, the overall averages of the five dimensions for expectation are higher than those of perception. The total gap is -0.280 for faculty of engineering. The electrical engineering has positive gap, it means that the study program has given good service to student. The lowest gap is -0.199 for civil engineering and the highest gap is -0.803 for industrial engineering. The negative gap indicates that a quality improvement program needs to be developed by study program. In the table 5, student satisfaction also is presented. The highest student satisfaction among faculty of engineering is 5.133 for civil engineering and the lowest is 4.936 for environmental engineering.

Table 6. Gap between student's expectations and perceptions for all of five dimensions

\begin{tabular}{llllllllllll}
\hline Dimension & \multicolumn{2}{c}{ Reliability } & \multicolumn{2}{c}{ Assurance } & \multicolumn{2}{c}{ Tangibles } & \multicolumn{3}{c}{ Empathy } & \multicolumn{3}{c}{ Responsiveness } \\
\cline { 2 - 10 } & Mean & SD & Mean & SD & Mean & SD & Mean & SD & Mean & SD \\
\hline Elect. Eng. & & & & & & & & & & \\
Perception & 5.141 & 0.896 & 5.011 & 0.966 & 5.114 & 0.923 & 5.268 & 0.838 & 5.241 & 0.839 \\
Expectation & 5.264 & 1.080 & 5.016 & 0.972 & 4.901 & 0.966 & 5.178 & 0.920 & 5.243 & 0.889 \\
Gap & -0.124 & 1.393 & - & 1.401 & 0.211 & 1.376 & 0.090 & 1.217 & - & 1.220 \\
& & & 0.004 & & & & & & 0.002 & \\
\hline Ind. Eng. & & & & & & & & & & \\
Perception & 4.899 & 0.738 & 4.909 & 0.736 & 5.029 & 0.766 & 5.503 & 0.798 & 5.297 & 0.771 \\
Expectation & 5.858 & 0.888 & 5.785 & 0.885 & 5.882 & 1.007 & 6.128 & 0.906 & 6.041 & 0.886 \\
Gap & -0.959 & 0.990 & - & 0.996 & -0.852 & 1.016 & -0.627 & 0.929 & - & 0.935 \\
& & & 0.876 & & & & & & 0.781 & \\
\hline Env. Eng. & & & & & & & & & & \\
Perception & 5.173 & 0.982 & 4.941 & 0.950 & 4.962 & 0.918 & 5.120 & 0.839 & 5.142 & 0.948 \\
Expectation & 5.314 & 0.867 & 5.233 & 0.715 & 5.145 & 0.868 & 5.290 & 0.795 & 5.398 & 1.029 \\
$\quad$ Gap & -0.141 & 1.03 & - & 1.110 & -0.183 & 1.095 & -0.169 & 0.860 & - & 1.211 \\
& & & 0.293 & & & & & & 0.256 & \\
\hline Mech. Eng. & & & & & & & & & & \\
Perception & 5.231 & 1.121 & 4.989 & 0.940 & 5.000 & 0.939 & 5.205 & 0.883 & 5.115 & 0.926 \\
Expectation & 5.546 & 0.936 & 5.252 & 1.029 & 5.267 & 0.944 & 5.508 & 0.868 & 5.359 & 0.865 \\
Gap & -0.315 & 1.193 & - & 1.270 & -0.266 & 1.124 & -0.303 & 1.020 & - & 1.081 \\
& & & 0.262 & & & & & & 0.244 & \\
\hline
\end{tabular}




\begin{tabular}{lllllllllll}
\hline Civil Eng. & & & & & & & & & \\
Perception & 5.203 & 0.920 & 5.151 & 1.148 & 5.062 & 0.945 & 5.297 & 0.864 & 5.198 & 0.899 \\
Expectation & 5.508 & 0.906 & 5.403 & 1.361 & 5.229 & 0.997 & 5.490 & 0.832 & 5.375 & 0.907 \\
Gap & -0.305 & 1.055 & - & 1.352 & -0.166 & 1.122 & -0.193 & 0.827 & - & 0.910 \\
& & & 0.173 & & & & & & 0.178 & \\
\hline Fac. Eng. & & & & & & & & & & \\
Perception & 5.141 & 0.923 & 5.018 & 0.979 & 5.038 & 0.905 & 5.282 & 0.853 & 5.191 & 0.878 \\
Expectation & 5.504 & 0.956 & 5.338 & 1.089 & 5.276 & 1.007 & 5.518 & 0.914 & 5.464 & 0.944 \\
Gap & -0.363 & 1.183 & - & 1.283 & -0.238 & 1.194 & -0.236 & 0.997 & - & 1.084 \\
& & & 0.298 & & & & & & 0.273 & \\
\hline
\end{tabular}

The negative gap in all of five dimensions is shown in Table 6. The meaning of negative gap is that faculty of engineering does not provide good service to student. From Table 6, the lowest gapsare empathy $(-0.236)$ and the highest gapsare reliability $(-0.363)$. The most negative gaps of the five dimension are reliability and assurance which are related to the quality of the academic staff, their knowledge, and competences to perform reliable education service. The next lowest negative gap is responsiveness which is generally related to staff's sensitivity towards student, providing prompt services, and responding to students' needs. The least negative gap is empathy and tangibles. Empathy is related to the conduct of faculty and staff towards to student. The faculty and staff should give attention, help, and support to students. Tangibles is related to imply modernization of infrastructure and utilization information and communication technology.

Among study programs in the faculty of engineering (Table 6), Industrial engineering has the most negative gaps in all of five dimensions. It means that this study program needs to be developed a quality improvement program.

Table 7 and 8 shows that correlation between service quality, service quality dimensions, and student satisfaction. The value of $r$ could be negative or positive. The negative correlation implies that relation between service quality dimensions and student satisfaction is negatively linear, whereas positive correlation is that relation between service quality dimensions and student satisfaction is positively linear. According to Colton [16], the strength of correlation (r) between two variables is qualitatively divided into:

$\mathrm{r}=0.00-0.25$ no correlation or weak correlation

$\mathrm{r}=0.26-0.50$ mild correlation

$\mathrm{r}=0.51-0.75$ strong correlation

$\mathrm{r}=0.76-1.00$ very strong correlation

From Table 7 overall, perceptions and expectations are positively linear which if service quality dimensions increase, student satisfaction can be increased. Because of $p>0.01$, the correlation between service quality and student satisfaction is significant. The strength of the correlation of perceptions and expectations is weak. From the Table 8, it shows that the correlation above 0,2 is dimensions of tangibles and empathy. 
Table 7. Correlation between service quality and student satisfaction

\begin{tabular}{lll}
\hline Service Quality & $\mathbf{r}$ & $\mathbf{p}$ \\
\hline Perceptions & 0.203 & 0.000 \\
Expectations & 0.172 & 0.000 \\
\hline
\end{tabular}

Table 8. Correlation between five dimensions of service quality and student satisfaction

\begin{tabular}{lll}
\hline Dimension & r & p \\
\hline Perceptions & & \\
Reliability & 0.187 & 0.000 \\
Assurance & 0.131 & 0.005 \\
Tangibles & 0.207 & 0.000 \\
Empathy & 0.219 & 0.000 \\
Responsiveness & 0.181 & 0.000 \\
\hline Expectations & & \\
Reliability & 0.137 & 0.003 \\
Assurance & 0.179 & 0.000 \\
Tangibles & 0.175 & 0.000 \\
Empathy & 0.166 & 0.000 \\
Responsiveness & 0.156 & 0.001 \\
\hline
\end{tabular}

\section{Conclusion}

The SERVQUAL model was used for assessing service quality at the Faculty of Engineering, Andalas University and the existence of a negative gap between students' expectations and perceptions was determined. In conclusion, based on the results of the research it can be concluded that the research hypotheses is positively confirmed. A negative gap between students' expectations and perceptions of the service quality was identified based on the research results. This negative gap can be analyzed and used to identify in which areas service quality at the Faculty of Engineering needs to be improved. The most negative gaps are reliability that it means that the faculty of engineering should increase the quality of the academic staff, their knowledge, and competences to perform reliable education service.

There is the impact of service quality to student satisfaction in the Faculty of Engineering. Student satisfaction will be increased linearly if quality service quality is increased. The correlation between service quality and student satisfaction is significant but the correlation is weak.

\section{Acknowledgments}

The authors gratefully acknowledgement the financial support of The Institute of Educational Development and Quality Assurance Universitas Andalas through research scheme in 2019.

\section{References}

[1] Van der Wende, M.: Internationalization of higher education in the OECD countries: Challenges and opportunities for the coming decades. Journal of studies in International Education, 11(3-4), pp. 274-289 (2007) 
[2] Sampson, D.: Remarks for the National Coalition for Advance Manufacturing Washington, DC (2004)

[3] Beaumont, D.J.: Service Quality in higher education: Student's Viewpoint, University of Manchester, Manchester Business School, Manchester UK (2012)

[4] Douglas J., McClelland, R., Davies J.: The development of a conceptual model of student satisfaction with their experience in higher education. Quality Assurance in Education, 16 (1), pp. 19-35 (1993)

[5] Yeo, R.K., Li, J.: Beyond SERVQUAL: The competitive forces of higher education in Singapore. Total Quality Management and Business Excellence, 25 (1-2), pp. 95-123 (2012)

[6] Parasuraman, A., Zeithaml, V.A., Berry, L.L.: A conceptual model of Service Quality and its implication for Future Research, Journal of Marketing, 49, pp. 41-50 (1985)

[7] Harvey, L., Green, D.: Defining quality. Assessment and Evaluation in Higher Education, 18 (1), pp. 9-34 (1993)

[8] Yeo, R.K.: Brewing service quality in higher education: Characteristics ingredients that make up the recipe. Quality Assurance in Education, 16(3), pp. 266-286 (2008)

[9] O’Neill, M.A., Palmer, A.: Importance-performance analysis: A useful tool for directing continuous quality improvement in higher education, Quality Assurance in Education, 12(1), pp. 39-52 (2004)

[10] Sabina D., Samira F.: Quality assessment in higher education using SERVQUAL model, Management, 20 (1) pp. $39-57$ (2015)

[11] Hill F. M.: Managing service quality in higher education: the role of student as primary customer, Quality Assurance in Education 3 (3), pp. 10-21 (1995)

[12] Salami, S. O.: Discriminant analysis of academic abilities and work values of career choice of high school adolescents in Southwestern Nigeria, Journal of Personality Study and group Behaviour, 25, pp. 49-73 (2005)

[13] Babaei, D., Rahimian, H., Ahmad, A., Omar, Z., and Idris, K.: Ability mediation effects in relationships between human resource practices and service quality. Iranian journal of Management studies, 8 (1), pp. 5- 25 (2015)

[14] Carmines, E.G., Zeller, R.A.: In reliability and validity assessment (Quantitative application in social science), New York, Sage Publication (1979)

[15] Murphy, K., Balzer, W.: Rate error and rating accuracy, Journal of Applied Psychology, 71, pp. 619-624 (1989)

[16] Colton, T.: Statistics in Medicine, Litle Brown and Company, Boston, USA (1974) 